\title{
Gastric Sleeve Analysis as a Surgical Treatment for Obesity
}

\author{
Castañeda Cruz JA ${ }^{1 *}$, Montaño Pérez $\mathrm{L}^{1}$, Corina ${ }^{1}$, Rodelo Uraga $\mathrm{MF}^{2}$, Molina ${ }^{2}$ and Noyola $\mathrm{LD}^{2}$ \\ ${ }^{1}$ Gastroenterology, Jardines Hospital, Mexico \\ ${ }^{2}$ Medicine School, Universidad Autónoma de Guadalajara, México
}

Submission: January 01, 2019; Published: January 10, 2019

*Corresponding author: Castañeda Cruz JA, Gastroenterology, Jardines Hospital, Zapopan, Jalisco, Mexico

Abstract

Introduction: Obesity is defined as the abnormal or excessive accumulation of fat that can be harmful to health. It is estimated that about 10 million people are severely obese in Mexico. Gastric Sleeve (GS) is the main procedure performed worldwide and has shown excellent results in treating obesity.

Materials and methods: This are a retrospective study carried out by "Gastric Bypass Mexico" medical group from 2014 to 2016, where records of 1,030 patients who underwent a GS by 3 surgeons under the same technique were reviewed; Patients who were not approved by the multidisciplinary team were excluded.

Results: A total of 1,032 surgeries were performed, 814 (79.03\%) to women; the averages are: age - 35.01 years old; BMI 40.16Kg / m2 (30$90.56 \mathrm{~kg} / \mathrm{m} 2)$; intra hospital stay 1.11 (1-5) days; surgical time 20.01 (15-35) minutes, anesthetic time 37.50 (30-102) minutes. The mortality rate was $0 \%$ and the complications percentage was 3.20\% (33): 20 (1.94\%) patients had bleeding, of which 7 (35\%) required a globular package transfusion (1-3 units); $10(0.97 \%)$ patients had an infection in a surgical wound, $2(0.19 \%)$ had gastropleural fistula and $1(0.97 \%)$ patient had a gastric leak.

Discussion: A GS is a safe and effective procedure for treating and controlling obesity. Compared to other techniques, a GS involves reduced anesthetic and surgical time, and offers short stays in the hospital.

Conclusions: A GS offers excellent weight loss results, with a low morbidity and mortality rate.

Keywords: Gastric Sleeve; Bariatric surgery; Obesity; Morbidity; Mortality; Gastropleural fistula; Anesthetic; Gastric Bypass Mexico; High blood pressure; Diabetes mellitus; Dyslipidemia; Heart failure; Venous insufficiency; Stroke; Gout; Coronary heart disease; Obstructive sleep; Apnea; Osteoarthritis

\section{Introduction}

Obesity is defined as the abnormal or excessive accumulation of fat that can be harmful to health. The Body Mass Index (BMI) is a simple pointer used to identify overweight and obesity in adults. The World Health Organization defines obesity in adults as the following: BMI equal to or greater than $30 \mathrm{Kg} / \mathrm{m} 2$ $[1,2]$. This is a conical disease, of a multifactorial nature, with an increasing prevalence in the world being the second cause of predictable death, after smoking. And great relevance in the world economy [3-6]. The main cause relies on changing the lifestyle of modern society, which has generated a huge unbalance between the consumption and use of energy, the development of large quantity and variety of industrial foods with a high caloric density, the enormous increase of sedentary lifestyle and less physical activity [7]. Obesity currently represents a major public health issue that has a serious impact on several countries' economy, it is associated with premature mortality, chronic morbidity, an increased use of health services, life quality deterioration and social stigmatization $[2,8,9]$; It has become a true epidemic of the 21st century and integrates what is known as the civilization syndrome $[1,10]$, so the World Health Organization now considers obesity as a global epidemic [11]. The prevalence of obese patients has severely increased becoming a serious public health issue [7]. It is estimated that in Mexico about 10 million people are severely obese $[4,6]$.

Fat is a toxic factor which increases the fragility of these patients [12]; Obese people suffer from an increased risk of presenting multiple comorbidities such as high blood pressure, diabetes mellitus, dyslipidemia, heart failure, venous insufficiency, stroke, gout, COPD, coronary heart disease, obstructive sleep apnea, osteoarthritis, development of insulin resistance, osteoarticular diseases, mood disorders, substance abuse, depression, anxiety, reproductive disorders and cancer, which diminishes the quality and life expectancy $[4,6,8,10,13]$. 


\section{Current Research in Diabetes \& Obesity Journal}

The effectiveness of dietary, pharmacological and behavioral treatment in morbid obesity is limited, so bariatric surgery emerges as an option for these patients $[8,14]$ since it is proven that this treatment can loss up to $83 \%$ of the weight within of the first year in addition to reducing comorbidities in $40 \%$ in 10 years (56\% of myocardial infarction, $92 \%$ for diabetes and $60 \%$ for cancer) $([13,15,16]$.

Laparoscopic vertical gastrectomy, or GS, is the most recent bariatric surgical procedure for obesity control [17-19] and stands out for being fast and safe $[2,17,20]$. In 2012, the American Society for Bariatric and Metabolic Surgery published a consensus in which it affirms that a GS is a valid alternative to a Gastric Bypass $[8,21,22]$, and has now demonstrated its effectiveness as an independent procedure for the treatment of morbid obesity [17]. The Vertical Sleeve Gastrectomy was first described in 1988 by Dr. Scopinaro [11]. The GS consists of a gastric resection of approximately $70-80 \%$ that leaves a narrow tube of limited volumetric capacity in the minor curvature $[17,23,24]$ which limits the stomach's discharge [25], meanwhile the integrity of structures such as duodenum, pylorus, antrum, minor curvature and vagus nerves, create a moderate restriction allowing a relatively normal eating behavior [11]. MG is not only a restrictive procedure due to a decrease in food intake secondary to gastric resection, since it also has a strong hormonal component because when the gastric fundus is almost completely resected, the production of the orexigenic and adipogenic hormones is reduced. called ghrelin (appetite regulating hormone) produced mostly in cells found in this site, which has an impact on increased gastric emptying, intestinal motility, changes in carbohydrate metabolism and loss of appetite; these two components have good results both in weight loss and in the control of comorbid phenomena [6$8,10,26,27]$.

A GS is not only a restrictive procedure due to the decrease in food intake secondary to the gastric resection, since it also has a strong hormonal component, because when the gastric fundus is almost completely resected, the production of the orexigenic and adipogenic hormones is reduced, which is known as ghrelin (appetite regulating hormone) produced mostly in cells found in this area, which has an impact on increasing the gastric evacuation, intestinal motility, changes in carbohydrate metabolism and loss of appetite; these two components have good results both in weight loss and in the control of comorbid phenomena $[6-8,10,26,27]$. It is estimated that only $1 \%$ of eligible patients undergo the surgery. The cause of this may be the false notion of unacceptable risks and high rate of associated complications [13]. A GS is a short time effective bariatric procedure, relatively safe since it is estimated that mortality rate for this bariatric surgery is less than $1 \%$ in reference centers, 5 to $10 \%$ of patients have acute complications and 9 to $25 \%$ late complications, patients also have a quick recovery $[6,12]$.

\section{Materials and Methods}

Retrospective and descriptive case study; It was carried out by the medical group at "Gastric Bypass Mexico" in Guadalajara, Jal. Mexico from 2014 to 2016. We reviewed records of 1,032 patients diagnosed with morbid obesity who underwent Vertical Gastrectomy in Laparoscopic Sleeve, under the same surgical technique.

The indications for the intervention meet the criteria for Mexico's “Clinical Practice Guideline - Surgical Treatment of Morbid Obesity", which were carried out with the due preoperative care by the multidisciplinary team, also variables such as gender, age and BMI, surgical time, days of hospital stay, complications and deaths.

The preoperative study case consisted of clinical analysis and a complete multidisciplinary assessment; Patients who were not approved by this team were excluded.

\section{Surgical technique}

General anesthesia, asepsis and antisepsis of the abdominal region and reversed Trendelenburg position. Ethicon Endosurgery ports, Cincinnati, OH Endophat Xce Bladeless Trocars were used, which were placed as follows: The first port of $12 \mathrm{~mm}$ supraumbilical, to the left of the midline to $15 \mathrm{~cm}$ below the rib cage with an open technique, insufflating with $\mathrm{CO} 2$ to obtain a pneumoperitoneum of $15 \mathrm{mmHg}$. The port for the $12 \mathrm{~mm}$ camera to the right of the midline in the middle of the distance between the xiphoid appendix and the umbilical scar. The port for the Surgeon's left hand is $5 \mathrm{~mm}$ left subcostal. The port for subxifoid hepatic retractor is of 5 or $10 \mathrm{~mm}$. One or two ports of $5 \mathrm{~mm}$ for the first assistant, the first left subcostal at the level of the anterior axillary line, and the additional port, if required, $10 \mathrm{~cm}$ below the previous one.

The liver is retracted in a cephalad orientation with a 10 $\mathrm{mm}$ blunt rod. Using a harmonic scalpel, the dissection of the greater curvature between 2 and $5 \mathrm{~cm}$ proximal to the pylorus is performed, until the angle of His and the left pillar are identified and dissected. Afterwards, a 32-36 Fr orogastric tube is placed in the minor curvature to the pylorus, to calibrate the gastric resection. Between 2 and $5 \mathrm{~cm}$ of the pylorus, the gastric resection is done with stapler (Echelon $60 \mathrm{~mm}$ Endophat with golden cartridge $3.8 \mathrm{~mm}$ ) up to the angle of His. In average, between 5 and 6 cartridges are used to obtain a gastric reservoir with a capacity of 50 to $60 \mathrm{ml}$. In case of a revision surgery we use a green cartridge of $4.1 \mathrm{~mm}$. In case the staple line has bleeding during the revision surgery, we reinforce the line of staples with monocryl suture 2 zeros (Ethicon). The hermeticity is checked with blue methylene, and the surgical piece is extracted through the port of the surgeon's right hand. Finally, the wounds are sutured with monocryl 3 zeros. An esophagogastroduodenal series is carried out with water-soluble material 24 hours after 


\section{Current Research in Diabetes \& Obesity Journal}

the procedure in order to review the anatomy and integrity of the gastric tube and dismiss leaks and obstruction. If no complications are found, clear liquids to tolerance are begun orally.

\section{Statistical analysis}

For statistical analysis, percentage, average and standard deviations are included for descriptive inference purposes.

\section{Results}

A total of 1,040 GS procedures were performed, in which 5 $(0.45 \%)$ of them also had a cholecystectomy surgery, $4(0.39 \%)$ a gastric band removal, 3 (0.29\%) GS readmissions and 2 (0.19\%)

Table 1: General Results. of them had a gastric balloon removed, where it was found that women are operated up to 3 times more than men 814 (79.03\%), the average age of patients is 35.01 years; Regarding the BMI the average is of 40.16 , and the highest BMI being operated was of a female patient with a BMI of $90.56 \mathrm{Kg} / \mathrm{m} 2$. With reference to the previous metabolic surgeries, we found $24(2.32 \%)$ of the patients had undergone them in an average surgical time of 20.01 minutes with a minimum of 15 minutes, and a maximum of 94 minutes with an average anesthetic time of 37.50 minutes; In addition, within the hospital stay, an average of 1.11 days was found, with a minimum of 1 and a maximum of 5 days. It should be noted that there were no re-admissions, both surgical and non-surgical (Table 1).

\begin{tabular}{|c|c|c|c|c|c|c|c|}
\hline Patients & Sex & Average Age & BMI Kg/m² & $\begin{array}{l}\text { Procedure } \\
\text { Time }\end{array}$ & Anesthetic Time & Days of Stay & $\begin{array}{c}\text { Previous Metaboic } \\
\text { Surgery }\end{array}$ \\
\hline 1032 & 814 women $(79.03 \%)$ & 35.01 & 40.16 & $20.01 \mathrm{~min}$ & $37.50 \mathrm{~min}$ & 1.11 & 24 \\
\hline & 218 men $(21.16 \%)$ & & $90.56 \mathrm{MAX}$ & $15 \pm 94$ & $15 \pm 102$ & $1 \pm 5$ & $2.32 \%$ \\
\hline
\end{tabular}

It should be noted that the morbidities were reduced in number with only $3.20 \%$ and we classified them into two groups, the first with the minor ones which occurred in only $2.91 \%$ of the total number of patients which are the following: Superficial bleeding in 20 patients representing 1.94\% of which 7 (35\%) required globular pack transfusion (1-3 units), and $10(0.97 \%)$ patients had an infection at the surgical site. In the second group of major complications, only three were came up: Two gastropleural fistulas $(0.19 \%)$ and a gastric leak $(0.10 \%)$ in the total of patients, in these a surgical reintervention was performed in each of them, without eventualities, which increased the hospital stay of each patient to five days

Table 2: Morbidity and mortality of a GS.

\begin{tabular}{|c|c|c|}
\hline Total of complications & & $\mathbf{3 3} \mathbf{( 3 . 2 0 \% )}$ \\
\hline \multirow{3}{*}{ Minor complications } & Superficial bleeding & $20(2.91 \%)$ \\
\cline { 2 - 3 } & $\begin{array}{c}\text { Infection at the surgical } \\
\text { site }\end{array}$ & $10(0.10 \%)$ \\
\hline \multirow{2}{*}{ Major complications } & Gastropleural fistulas & $2(0.29 \%)$ \\
\cline { 2 - 3 } & Gastric leakage & $1(0.10)$ \\
\hline \multirow{2}{*}{ Deaths } & & $0(0 \%)$ \\
\hline
\end{tabular}

Other major complications such as pulmonary thromboembolism, ulcer, etc. were non-existent. There were no deaths, so the mortality is $0 \%$ (Table 2 ).

\section{Discussion}

Bariatric surgery has proven to be the most effective treatment for obesity, even in its most severe categories. In addition to reducing excess weight, it achieves a high rate of improvement and remission of metabolic comorbidities, which improves the quality and life expectancy of the operated patients [7]. The GS is a relatively new procedure and has become one of the bariatric procedures of choice for treating obesity $[7,8,10]$.
The number of bariatric surgeries has increased systematically every year, so the morbidity and mortality of these patients should be considered, as well as the risk of benefit $[2,6,28]$.

It was found in literature that the complication rate of a GS ranges from $2.2 \%$ to $15.1 \%[7,10,11,27]$, our percentages of comorbidities is $3.20 \%$, which is considered to be relatively low. Some authors indicate that the greater percentage of these are presented in the groups of patients with a previous bariatric surgery [11]; however, for us, no patient with these characteristics presented any complication.

A GS is considered to be a safe procedure for its comorbidities; among the specific complications of bariatric surgery include: fistulas (2.4-4\% and up to $8 \%$ in conversion surgeries), marginal ulcer $(2.4 \%)$, bleeding (1-4\%), infections (4\%), intestinal obstructions, pulmonary embolism, among the most important $[7,11-13,26,29,30]$. In this case study, serious complications (fistula and leakage) represent $0.29 \%$ of the total of surgeries; the incidence of fistulas is lower than in other techniques, it is advisable to have meticulous attention with the suture line, to control hemostasis and prevent leakage since these can cause a significant increase in morbidity [11], while the minor ones are $2.91 \%$.

It is noteworthy that most of these complications were superficial bleedings that were managed with globular concentrates without requiring additional therapy. The infections shown in our patients were only located in the surgical site in $0.10 \%$ of the them, in general the infections of the operative area are observed between $2-5 \%$ of the operated patients; this condition doubles the risk of dying, and increases the hospital stay by 5-7 days, which causes a significant increase in the cost associated with the surgical intervention [12]. As expected, there were no non-surgical reinterventions and the surgical ones were relatively rare, three in total without presenting 
another eventuality [11]. Mortality in laparoscopic bariatric surgery is a relatively rare event [22], its general percentage varies between 0 and $2.0 \%$, this rates are mainly related to the production of fistulas and peritonitis in its great majority (75\%) $[6,11,27,31]$; In our patients none of these situations occurred, this is attributed to the operative technique and the experience of the surgical and multidisciplinary team.

The GS is a procedure with a restrictive and hormonal component with an acceptable operative time that takes between one and two hours $[8,11]$; With an average surgical time of 20.01 minutes, our team is faster than most times analyzed in the literature $[8,10,11,21,22,28]$. This in turn helps reduce the average anesthetic time to 37.50 minutes.

Some authors indicate that their average hospitalization stay is up to 4 days $[27,28]$ and ours is 1.1 days; it is proposed that the brief hospital stay of our patients is due to the shorter surgical and anesthetic time, which reduces both operative and nosocomial complications and the recovery time.

\section{Conclusion}

A GS offers excellent results in long-term weight loss $[10,26]$, as well as low morbidity and mortality. The low rate of complications in our patients is attributed to the experience and technique of our surgical team as well as the care of the multidisciplinary team.

The brief hospital stay of our patients represents a lower economic cost and decreases the probability of acquiring a nosocomial infection, these two conditions are attributed to the decrease in anesthetic and surgical time.

Bariatric surgery is currently at a peak and opens the way for metabolic control $[2,10,31]$ specifically GS, it is a safe procedure due to its low rate of complications and mortality, which is why it is recommended as an excellent alternative for an obesity treatment to increase the quantity and quality of life $[21,22]$.

\section{References}

1. Kozlowski T, Kozakiewicz K, Dadan J, Mysliwiec P (2016) Innovative solutions in bariatric surgery. Gland Surg 5(5): 529-536.

2. Argüello ABA, Zúñiga AV (2016) Cirugía Bariátrica: Generalidades. Medicina Legal de Costa Rica 33(1): 145-153.

3. Campos Jara C, Delgado Floody P, Caamano Navarrete F, Guzman Guzman I, Cesp Barria M, et al. (2016) Alterations in the physical performance of students: The Test Cafra and Navette and association with obesity and cardiometabolic risk. Nutr Hosp 33(4): 374.

4. Domínguez-Reyes T, Teresa QVI, Salgado-Bernabé A, Salgado-Goytia L Muñoz-Valle J, et al. (2017) Anthropometric measurements as predictive indicators of metabolic risk in a Mexican population. Nutr Hosp 31(1): 96-101.

5. León RT, Zumaeta VA, Ruiz PS (2017) The complex relationship between mental health and weigth loss surgery. A review. Revista chilena de cirugía 69(2): 174-180.

6. Salud MSd (2009) Tratamiento Quirurgico del paciente adulto con Obesidad Mórbida. CENETEC.
7. Nuño M, Hevia M, Bustos C, Florenzano R, Fritsch R (2017) Distorted body image of overweight or obese children among mothers. Revista chilena de nutrición 44(1): 28-32.

8. Olguín VP, Carvajal AD, Fuentes SM (2015) Bariatric surgery and mental disorders. Rev Chil Cir 67(4): 441-447.

9. Núnez KR (2016) Riesgo de Suicidio Posterior a una Cirugía Bariátrica. Medicina Legal de Costa Rica 33(1): 139-144.

10. Elbanna H, Ghannam W, Negm A, Youssef T, Emile S, et al. (2016) Impact of preoperative body mass index on the final outcome after laparoscopic sleeve gastrectomy for morbid obesity. Ulus Cerrahi Derg 32(4): 238-243.

11. Nelson L, Moon RC, Teixeira AF, Galvao M, Ramos A, et al. (2016) Safety and Effectiveness of Single Anastomosis Duodenal Switch Procedure: Preliminary Result from a Single Institution. Arq Bras Cir Dig 29(Suppl 1): $80-84$.

12. Julio Yarmuch EL, Manuel Figueroa (2016) Infecciones en cirugía bariátrica. Revista Chilena de Cirugía 68(5): 390-393.

13. Ma IT, Madura JA (2015) Gastrointestinal Complications After Bariatric Surgery. Gastroenterol Hepatol (N Y) 11(8): 526-535.

14. Baltasar A, Dominguez-Adame E (2013) Beginnings of bariatric and metabolic surgery in Spain. Cir Esp 91(7): 413-416.

15. Netto BD, Bettini SC, Clemente AP, Ferreira JP, Boritza K, et al. (2015) Roux-en-Y gastric bypass decreases pro-inflammatory and thrombotic biomarkers in individuals with extreme obesity. Obes Surg 25(6): 1010-1018.

16. Sanchez-Pernaute A, Rubio MA, Cabrerizo L, Ramos-Levi A, Perez-Aguirre E, et al. (2015) Single-anastomosis duodenoileal bypass with sleeve gastrectomy (SADI-S) for obese diabetic patients. Surg Obes Relat Dis 11(5): 1092-1098.

17. Barzin M, Khalaj A, Motamedi MA, Shapoori P, Azizi F, et al. (2016) Safety and effectiveness of sleeve gastrectomy versus gastric bypass: oneyear results of Tehran Obesity Treatment Study (TOTS). Gastroenterol Hepatol Bed Bench 9(Suppl1): S62-S69.

18. Brethauer SA, Hammel JP, Schauer PR (2009) Systematic review of sleeve gastrectomy as staging and primary bariatric procedure. Surg Obes Relat Dis 5(4): 469-475.

19. Janik MR, Stanowski E, Pasnik K (2016) Present status of bariatric surgery in Poland. Wideochir Inne Tech Maloinwazyjne 11(1): 22-25.

20. Caracela Zeballos CR, Dieguez Tapias S, Cereceda Perez CN, Pinto Varela JM (2014) Laparoscopic gastric bypass: computed tomography appearance of common postoperative changes and complications. Radiologia 56(5): 413-419.

21. Committee AT, Thosani N, Abu Dayyeh BK, Sharma P, Aslanian HR, et al. (2016) ASGE Technology Committee systematic review and meta-analysis assessing the ASGE Preservation and Incorporation of Valuable Endoscopic Innovations thresholds for adopting real-time imaging-assisted endoscopic targeted biopsy during endoscopic surveillance of Barrett's esophagus. Gastrointest Endosc 83(4): 684-698.

22. Force ABET, Committee AT, Abu Dayyeh BK, Kumar N, Edmundowicz SA, et al. (2015) ASGE Bariatric Endoscopy Task Force systematic review and meta-analysis assessing the ASGE PIVI thresholds for adopting endoscopic bariatric therapies. Gastrointest Endosc 82(3): 425438.

23. Peterli R, Borbely Y, Kern B, Gass M, Peters T, et al. (2013) Early results of the Swiss Multicentre Bypass or Sleeve Study (SM-BOSS): a prospective randomized trial comparing laparoscopic sleeve gastrectomy and Roux-en-Y gastric bypass. Ann Surg 258(5): 690-694.

24. Vilallonga R, Yeste D, Lecube A, Fort JM (2012) Bariatric surgery in adolescents. Cir Esp 90(10): 619-625. 


\section{Current Research in Diabetes \& Obesity Journal}

25. Bussey CE, Withers SB, Aldous RG, Edwards G, Heagerty AM (2016) Obesity-Related Perivascular Adipose Tissue Damage Is Reversed by Sustained Weight Loss in the Rat. Arterioscler Thromb Vasc Biol 36(7): 1377-1385.

26. Lorente L, Ramon JM, Vidal P, Goday A, Parri A, et al. (2014) Obesity surgery mortality risk score for the prediction of complications after laparoscopic bariatric surgery. Cir Esp 92(5): 316-323.

27. Dakwar A, Assalia A, Khamaysi I, Kluger Y, Mahajna A (2013) Late complication of laparoscopic sleeve gastrectomy. Case Rep Gastrointest Med 2013: 136153

28. de la Matta-Martin M, Acosta-Martinez J, Sanchez-Carrillo F (2014) Anesthesia for bariatric surgery: 8-year retrospective study: are our patients now easier to manage? Rev Esp Anestesiol Reanim 61(8) 422-428.
29. Vilallonga R, Yeste D, Lecube A, Armengol M, Fort JM (2013) A bariatric surgery programme in adolescents. Preliminary results. Cir Esp 91(10): 685-687

30. Zhang H, Wang Y, Zhang J, Potter BJ, Sowers JR, et al. (2011) Bariatric surgery reduces visceral adipose inflammation and improves endothelial function in type 2 diabetic mice. Arterioscler Thromb Vasc Biol 31(9): 2063-2069.

31. Brethauer SA, Kothari S, Sudan R, Williams B, English WJ, et al. (2014) Systematic review on reoperative bariatric surgery: American Society for Metabolic and Bariatric Surgery Revision Task Force. Surg Obes Relat Dis 10(5): 952-972.

Your next submission with Juniper Publishers
will reach you the below assets
- Quality Editorial service
- Swift Peer Review
- Reprints availability
- E-prints Service
- Manuscript Podcast for convenient understanding
- Global attainment for your research
- Manuscript accessibility in different formats
( Pdf, E-pub, Full Text, Audio)
- Unceasing customer service
Track the below URL for one-step submission
https://juniperpublishers.com/online-submission.php

(1)

